International Journal of Engineering \& Technology, $7(4.33)(2018) 119-122$
International Journal of Engineering \& Technology
SPC
Website: www.sciencepubco.com/index.php/IJET
Research paper

\title{
The Design and Implementation of Massive Open Online Course (MOOC) for Ordinary Differential Equations (ODE)
}

\author{
Junaida Md Said*, Elizabeth Arul, Samsiah Abdul Razak, Nur Azila Yahya, Nurul Husna Jamian \\ Faculty of Computer and Mathematical Sciences, Universiti Teknologi MARA, Perak Branch, Tapah Campus, Tapah Road, \\ 35400 Perak, Malaysia \\ *Corresponding author E-mail: junai642@perak.uitm.edu.my
}

\begin{abstract}
Ordinary Differential Equations (ODE) is taken by students in the mathematics, science or engineering programs in Universiti Teknologi MARA (UiTM). This course was originally taught in the traditional way with the lecturer as the instructor. In 2014, this course evolved into the blended-learning mode i.e. a combination of classroom sessions and online sessions using the university learning management system. In 2017, a team of lecturers in the Tapah campus of UiTM decided to develop an instructional design of ODE using the MOOC platform. Students would then use the MOOC during the blended-learning hour. Five modules are offered in this MOOC. Lecture notes are presented using Prezi together with instructional videos and self-checking exercises. 55 students enrolled for the MOOC and were surveyed to gauge the initial impact of the MOOC as an instructional tool. More than $50 \%$ of the students said that the MOOC absolutely helped them to better understand the classroom sessions. Most of the students put in maximum effort in accessing the MOOC. The MOOC also helped to build up self-confidence of students in the course material. It is hoped that as the MOOC is further refined and improved, more students will benefit from the MOOC.
\end{abstract}

Keywords: Ordinary Differential Equations (ODE); Blended learning; MOOC; Open Learning; Higher education.

\section{Introduction}

This study focuses on teaching and learning Ordinary Differential Equations (ODEs). Differential Equations (DEs) is one of the core courses in the curriculum for undergraduate students majoring in mathematics, science or engineering. This course has been offered to full-time Diploma students in Mathematical Sciences (CS143), Universiti Teknologi MARA (UiTM) since 2012. The most difficult part of learning this course is the solution processes that are often long and tedious, drawing heavily on material from calculus and linear algebra. Typically, the course has been taught in a conventional method, with the lecturer developing a collection of algorithms to solve ODEs and working out examples by hand on the board. Explanations tend to be time-consuming, and so the lecturer must often restrict the examples to simpler problems. This approach leaves little time for classroom interactions with the student. In 2014, this course evolved into the blended learning mode. This blended learning approach combines face-to-face learning with online learning. In order to design this blended course, the university learning management system (LMS) called i-Learn was used. LMSs have been adopted by universities all over world at a remarkable rate [1]. Students meet face to face for three hours with one hour of blended learning per week. The content providers during the blended hour include online activities or quizzes, discussion forums, traditional notes and videos. However, there are some challenges and limitations to blended learning using LMS. Firstly, it is difficult for the lecturer to monitor student engagement during the blended hour. Secondly, the challenging part in using blended learning is the method of content delivery since functions can only be presented in picture format or by recording videos for the stu- dents to watch. According to [2], incompetent use of LMSs (especially the posting of static content on an LMS) has been criticized. The LMS-centric model of learning has failed to improve performance [3].

Technology has continued to transform traditional education and online settings [4] as the recent proliferation of massive open online courses (MOOCs) demonstrate. There is growing interest for exploring how MOOCs can be utilized to implement a mode of blended learning [5]. The promises behind MOOCs stand on delivering free and open education to the public, as well as training a large criterion of students [6]. The aims of MOOC is i) promoting educational innovation $[7,8]$; ii) stimulating reflection on the use of technology in the classroom and with the students; and iii) the creation of a community of practice and sharing. It has driven academicians in UiTM to grab this opportunity to implement MOOC for their courses.

Many educators in Malaysia have now started to design and create courses using MOOCs in various disciplines. This paper aims to discuss the instructional design of the MOOC for ODE at UiTM, Tapah. It also reports student reaction and response toward MOOC for ODE.

\section{A Brief overview of MOOCs}

\subsection{Blended Learning with MOOCs}

Blended learning is the integration of traditional classroom method and independent study through online learning with the use of technology and various learning materials for students and lecturers $[9$, 10]. During the blended learning hour, the lecturer has to prepare online learning materials and activities. Instead of using LMS, 
MOOCs present a new option for blended course design. MOOC is an online program free from payment and needs no special requirement other than having internet access [11]. According to [12], MOOCs contain a variety of materials for instance, reading materials, videos, problems and discussions to encourage a user-built learning community for students.

The successfulness of the blended learning model can be achieved by mixing the MOOC technology with traditional class as a way of transforming and improving education. MOOCs offer challenging opportunities to academicians for improving their knowledge in their own area of expertise, improve competencies and skills for adopting new models of open educational practices. However for the students, MOOCs are very useful. The open learning platform will enable anyone anywhere to access this module independently at any time. The main weakness of MOOC is limited interaction between lecturers and students and also requires high self-discipline on the part of students [13].

MOOCs also make life-long learning available for all and are also a new supportive tool in Teaching \& Learning (T\&L) activities in universities, especially for Mathematics students at their own pace. In other words, MOOCs offer learning aids to their personal learning environment [14].

\subsection{Ordinary Differential Equation MOOC}

Differential equations are widely used in a variety of fields. For in stance, problems involving thermodynamic changes, population growth and spread of disease are modelled by differential equations. Teaching and learning of differential equations is a difficult part in any mathematics course, particularly at pre-university level [15].

Besides that, according to UiTM Tapah Academic Records, we have noticed that periodically, certain batches of students perform poorly in this course. In order to help poorly-performing students, an online course was created so that students can access course materials anytime anywhere. As mentioned in the introduction, due to the long-standing ODE problem, MOOC is beneficial for the subjects that are mathematically nontrivial and conceptually difficult and where the essential part of competence is the ability to carry out complex calculations [13]. Open learning is a MOOC provider that has been used as a teaching and learning platform for ODE which is useful for the BL mode. The main features of MOOC are course information, learning materials and assessment activities which are all elements adapted from the National Learning Policy.

\section{The Design of ODE-MOOC}

Massive Open Online Courses (MOOCs) have attracted a great deal of attention by higher education and private enterprises. MOOCs have evolved considerably since their emergence in 2008, all the while given rise to academic discussions on MOOC impact, design and reach. However, most MOOCs still need the support of face to face lectures as the main medium of learning [12]. It is because learning through MOOC is actually a complex process. Thus, to overcome this problem, the instructor should use more effective methods of learning to encourage students to think critically. Compared to conventional classrooms, students in the MOOC environment tend to be more active where they learn independently with the aid of technology while the instructors act as facilitators.

The course materials consist of short video lectures, worked examples and several tests and exercises. MOOC for ODE embraces 5 different modules/lessons, with 8 sets of lecture notes in the form of Prezi, with 13 videos and 24 activities, distributed throughout the following topics:

- Introduction

- First Order Differential Equations

- Applications of First Order Differential Equations

- Higher Order Differential Equations

- Applications of Second Order Differential Equations
The homepage of Introduction to Ordinary Differential Equations course is presented in Fig. 1. All modules have a similar structure as visualized in Fig. 2; they present an ordered set of lecture notes in the form of Prezi with voice-over as shown in Fig. 3 and short videos as shown in Fig. 4 demonstrating solutions of selected examples. After going through the Prezi and watching videos as many times as they please, students can try a simple activity that is provided and apply the concepts addressed in Prezi and the videos as shown in Fig. 5(1) and Fig. 5(2). In relation to these simple activities, students can have multiple attempts at each one of them. Indirectly, it helps transform the process into an educational activity instead of a simple assessment.

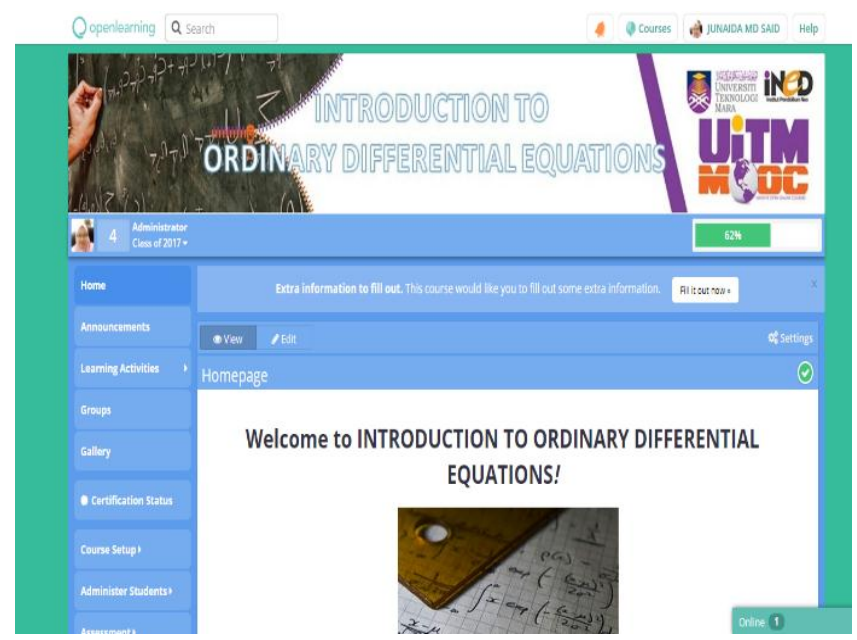

Fig. 1: Screenshot from homepage of MOOC for ODE course.

Fig. 2 shows the screenshot of the Learning Structure of modules. The lecture materials provided are similar for all modules where there are slide presentations in the form of Prezi, short videos of solutions for selected examples and activities consisting of exercises that students may attempt after learning from slide presentations to increase their understanding. The quizzes and assessment problems help to ensure that concepts are understood.

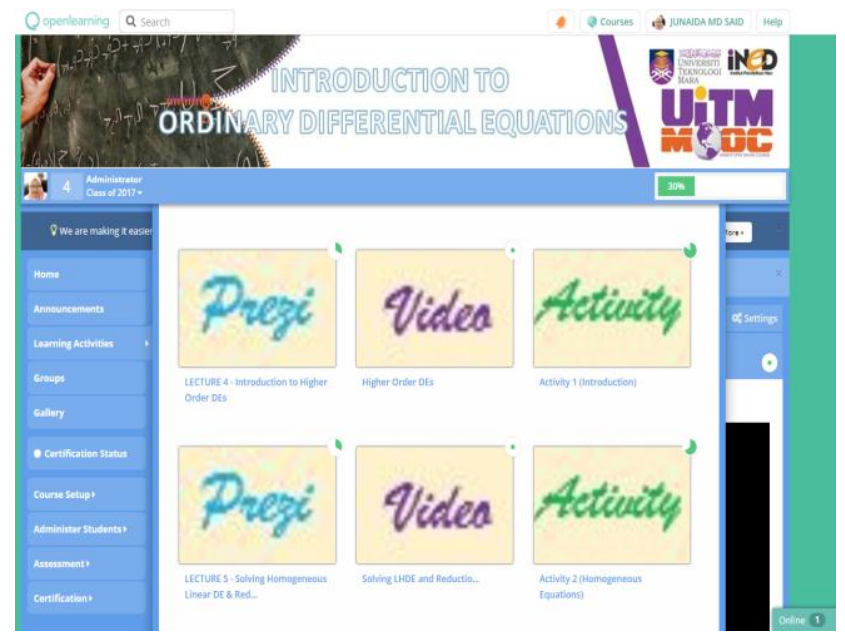

Fig. 2: Screenshot of the Learning Structure of modules.

The lecture notes or slides in MOOC are similar to those used in the conventional classroom lectures in the form of presentations prepared for each week of class. However, lecture materials prepared in MOOC are in the form of Prezi (online presentation tools) which is a great presentation tool that brings ideas to life. This will encourage students to be more involved in their own learning both before and after attending class. Fig. 3 displays the screenshot of one of topics covered in ODE i.e. First Order Differential Equations using Prezi presentation software. 


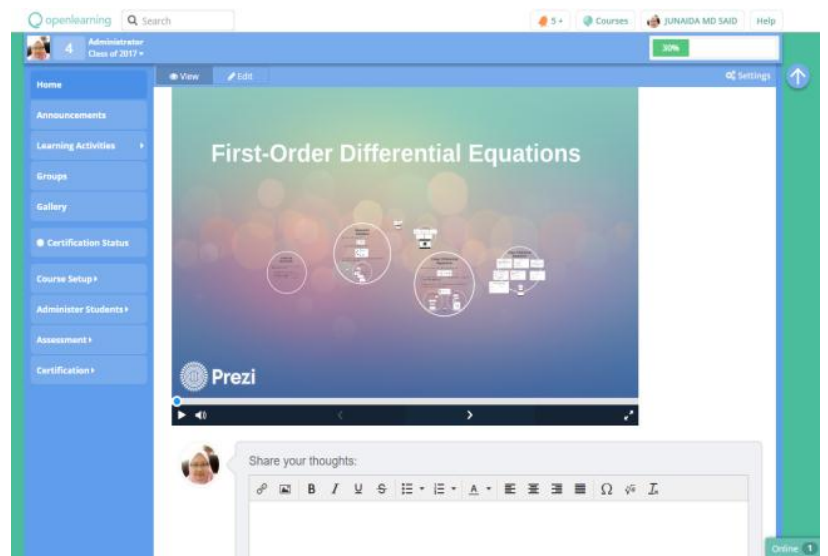

Fig. 3: Screenshot of the Lecture Materials in the form of Prezi

In addition, short videos have been prepared to demonstrate solutions for particular examples to guide the students through the solution process so that they can solve other examples given in the MOOC as shown in Fig. 4.

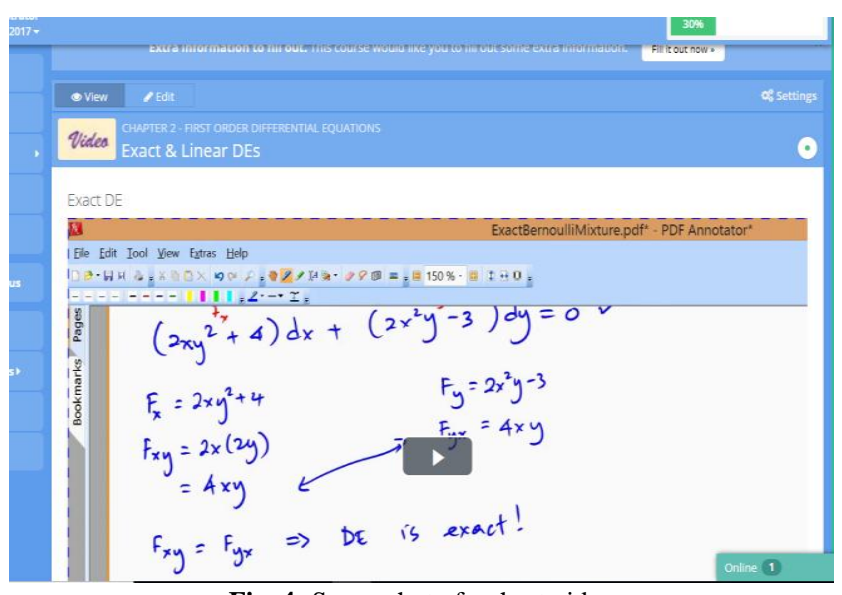

Fig. 4: Screenshot of a short video

The learning activities included in MOOC are assignments and quizzes for every module in ODE. These activities are used to help the students in the learning process and they can also be used to assess the progress of students undertaking this course. The instant feedback assessments consist of true-false, multiple choice and matching questions and are designed to engage the students and encourage them to try the questions repeatedly until they get the correct answer. Fig. 5(a-b) show the screenshots of some of the learning activities in this course.

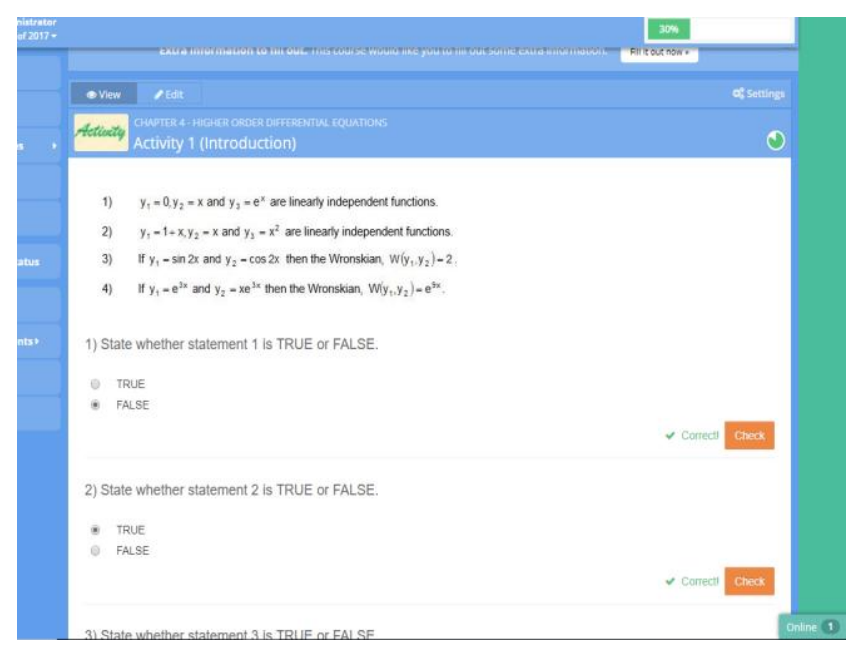

Fig. 5(a): Screenshot of Learning Activities

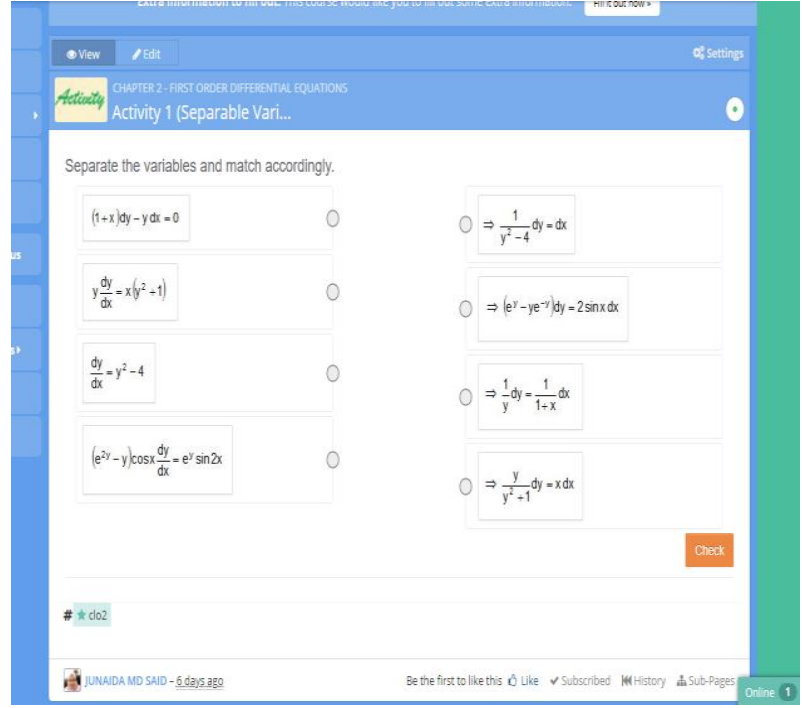

Fig. 5(b): Screenshot of Learning Activities

\section{Methodology}

The purpose of this study was to instructionally design a MOOC for the ODE course coded as MAT300 in UiTM, Tapah and present students' reaction and response towards MOOC for ODE based on three research constructs: students' effort in accessing MOOC, students' understanding and students' confidence level. A total of 55 respondents who were undergraduate students enrolled for MAT300 course during the December 2016-March 2017 semester. This course is taken by semester five students as stipulated in the Diploma in Mathematical Sciences (CS143) curriculum plan. They were required to fill up a survey form on Google created by the lecturer in charge of the MAT300 course. Teaching and learning in the course consisted of blended face-to-face teaching lectures together with online participation through MOOC using the open learning platform. The course ran for 14 weeks with three hours face to face lectures and one hour blended (online) learning per week.

\section{Results and Discussion}

\subsection{Students' Understanding of MOOC}

This section describes students' understanding of MOOC for ODE (MAT300) in terms of content and teaching method. The learning materials used Prezi presentation with video recordings of the lessons. Based on Fig. 6, the study showed that $52.9 \%$ (27 students) of the students said MOOC absolutely helped them better understand what was taught face-to-face in class and $45.1 \%$ (23 students) stated that MOOC somewhat helped them. There was only one out of 55 students who responded that MOOC did not help at all.

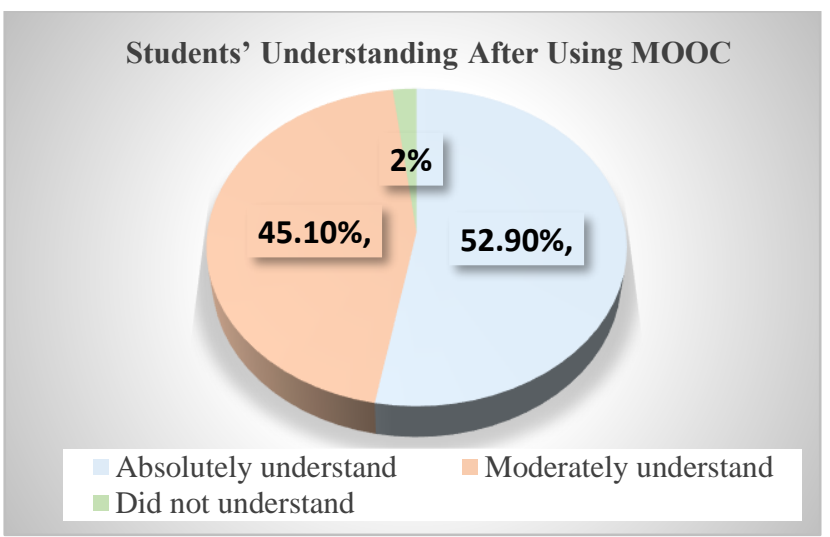

Fig. 6: Students' Understanding After Using MOOC 


\subsection{Students' Effort in Accessing MOOC}

This section focused on the students' effort in accessing MOOC for ODE (MAT 300). The study describes the level of effort that students put into going through online materials in MOOC outside of the class. Fig. 7 reveals that $62.80 \%$ (35 students) of the students put in maximum effort to access the online material, while $33.30 \%$ (18 students) put in good effort in accessing online material to help them understand the course outside class. Two out of 55 students put in little effort to access online material in MOOC for this course. Thus, this shows that most of the students put in effort to access the online materials in MOOC.

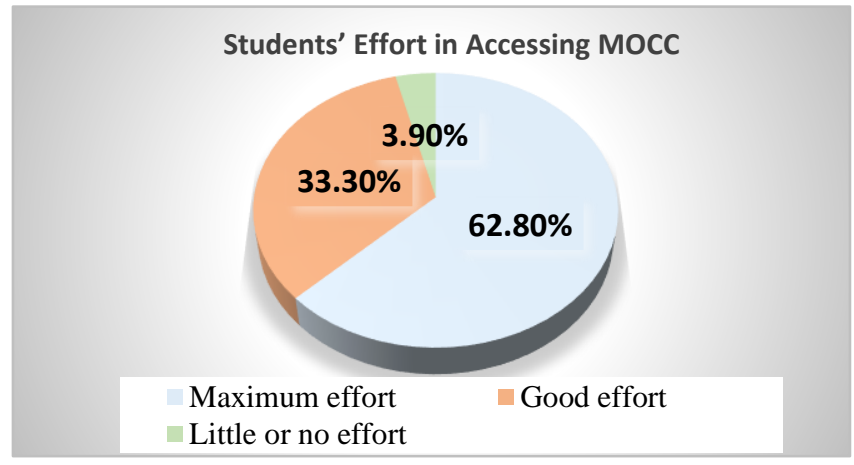

Fig. 7: Students' Accessibility Response of using MOOC

\subsection{Students' Confidence in ODE}

In this section, the researchers wanted to investigate how confident the students feel in the subject matter after viewing the online material in MOOC before and after going to class. Based on Fig. 8, $51.2 \%$ (28 students) were extremely confident and $43.9 \%$ (24 students) were moderately confident before attending class. Meanwhile, $52.8 \%$ (29 students) were extremely confident and 44.7\% (25 students) were moderately confident after attending class. However, $4.9 \%$ (3 students) had little or no confident before class and this dropped to $2.5 \%$ ( 1 student) after class. This suggests that viewing the online materials in MOOC increases students' confidence in the subject matter.

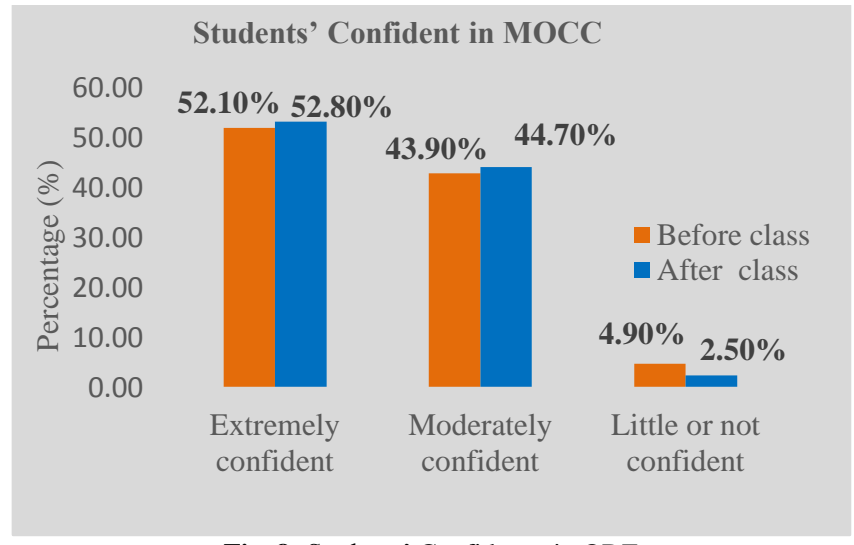

Fig. 8: Students' Confidence in ODE

\section{Conclusion}

This MOOC was specially designed for diploma level students in UiTM. Implementing the MOOC in a blended learning class resulted in positive feedback from students. It was beneficial to students in terms of preparation before class, internalization after class and revision before examination.

Some weaknesses were detected during the implementation of this MOOC. Many students did not complete all the modules. The lecturer as the MOOC instructor should take a more proactive role in discovering all the features the open learning platform has to offer to make it more interactive. However, these aspects can be improved upon as the instructors become more familiar with it.

A future study can be undertaken to gauge the effectiveness of the MOOC in terms of improvement in students' performance.

\section{Acknowledgement}

The authors would like to thank Universiti Teknologi MARA, Tapah Campus for giving them the opportunity, and providing the facilities that helped to develop and implement MOOC for ODE (MAT300) successfully. Heartfelt thanks also go out to lecturers and staff for their contribution and support during the MOOC development process.

\section{References}

[1] Coates H, James R \& Baldwin G (2005), A critical examination of the effects of learning management systems on university teaching and learning. Tertiary Education and Management 11(1), 19-36.

[2] Borba MC, Askar P, Engelbrecht J, Gadanidis G, Llinares S, Aguilar MS (2016), Blended learning, e-learning and mobile learning in mathematics education. ZDM Mathematics Education 48(5), 589610.

[3] Chatti AC, Agustiawan MR, Jarke M, \& Specht M (2010), Toward a personal learning environment framework. International Journal of Virtual and Personal Learning Environments 1(4), 66-85.

[4] Baldwin RG, (1998), Technology's impact on faculty life and work. New Directions for Teaching and Learning 76, 7-21.

[5] Bralić A, \& Divjak B (2016), Use of MOOCs in traditional classroom: Blended learning approach. In A. Volungeviciene, A. Sz Hucs, \& I. Mázár (Eds.), Forging New Pathways of Research and Innovation in Open and Distance Learning. Oldenburg: European Distance and E-Learning Network, pp. 34-43.

[6] Ebner M, Khalil M, Schön S, Gütl C, Aschemann B, Frei W \& Röthler D (2017), How inverse blended learning can turn up learning with MOOCs? Proceedings of the MOOC-MAKER 2017, pp. 21-30.

[7] Aldon G, Arzarello F, Panero M, Robutti O, Taranto E \& Trgalová J (2017), MOOC for mathematics teacher training: Design principles and assessment. Proceedings of the 13th International Conference on Technology in Mathematics Teaching, pp. 1-8.

[8] Spyropoulou N, Demopoulou G, Pierrakeas C, Koutsonikos I \& Kameas A (2015), Developing a computer programming MOOC. Procedia Computer Science 65, 182 - 191.

[9] Torrisi-Steele G \& Drew S (2013), The literature landscape of blended learning in higher education: The need for better understanding of academic blended practice. International Journal for Academic Development 18(4), 371 - 383.

[10] Bruff DO, Fisher DH, McEwen KE \& Smith BE (2013), Wrapping a MOOC: Student perceptions of an experiment in blended learning. Journal of Online Learning and Teaching, 9(2), 187-199.

[11] Kay J, Reimann P, Diebold E \& Kummerfeld B (2013), MOOC: So many learners, so much potential. IEEE Intelligent Systems 3, $70-$ 77.

[12] Pappano L (2012), The year of the MOOC, The New York Times, ED26. http://www.nytimes.com/2012/11/04/education/edlife/massive-open-online-courses-are-multiplyingat-a-rapid-pace.html.

[13] Ivo L, Irja H \& Lauri J (2015), Using MOOCs for teaching analytical chemistry: Experience at University of Tartu. Analytical and Bioanalytical Chemistry 407(5), 1277-1281.

[14] Morris NP (2014), How digital technologies, blended learning and MOOCs will impact the future of higher education. Proceedings of the International Conference e-Learning, pp. 401-404.

[15] Bibi A, Syed Zamri SNA, Mohammad Abedalaziz NA \& Ahmad M (2017), Teaching and learning of differential equation: A critical review to explore potential area for reform movement. International Journal for Innovative Research in Multidisciplinary Filed 3(6), 225 -235 . 